demonstration project of cooling existing PV power plants in Lisbon Portugal, where an increase of up to $12 \%$ of annual energy production was seen [10].

This paper presents the result of testing a cooling method using pulsating heat pipe (PHP). A pulsating heat pipe, also known as oscillating heat pipe (OHP), is a heat pipe partially filled with a suitable working fluid naturally distributed in the form of a liquid- vapor slug-plug system[11]. It was first proposed by Akachi in the early 1990s [12][13]. Figure 2 shows the typical schematic of a pulsating heat pipe.

A PHP operates when the evaporation side receives heat, the fluid in the capillary moves due to the uneven distribution of bubble and slugs in the tube and this movement transports the heat to the condenser [14]. However, the direction of movement is difficult to predict and research are being done in this area [14].

This project explores the potential of applying PHP for solar PV cooling, with the assumption that it can help increase the efficiency of the panel. The effect on the panel efficiency will be observed.

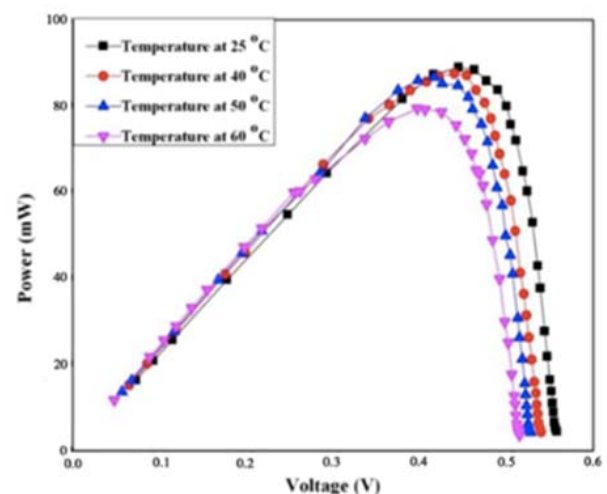

Figure 1. P-V characteristic of mono-Si solar cell with temperature [5]

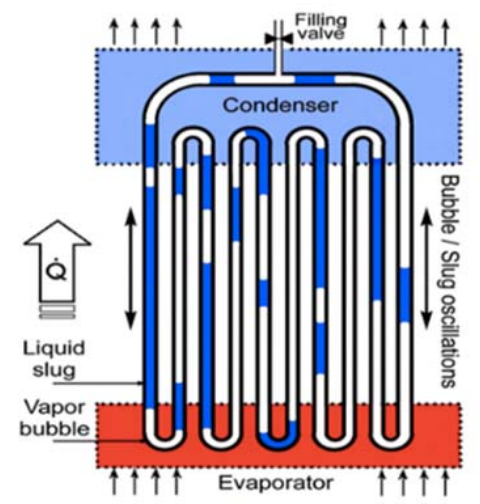

Figure 2. Typical pulsating heat pipe [15]

\section{RESEARCH METHOD}

Study is done by first designing the prototype, followed by its fabrication. Then, a suitable site is selected to conduct the experiment. The experiment was then set up and data is collected, followed by data analysis and a report is written at the end of the study.

Figure 1 shows the outline of the methodology for this study, followed by the explanation for each step of the process.

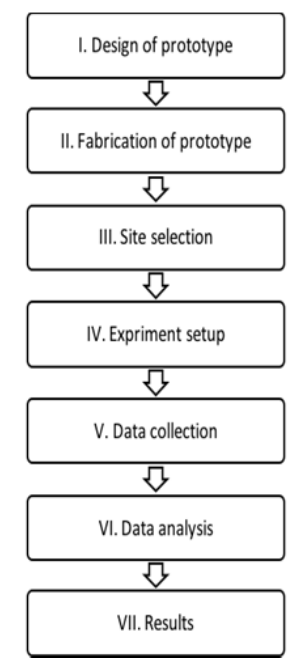

Figure 1. Methodology of study 
A sketch of the prototype was made using CREO Parametric, adding 200mm of height from the top of the panel. This additional is to be made a consideration when applying this cooling method in an array, where more space is needed for installation. The dimensions of the assembled system is as in Figure 4 below:

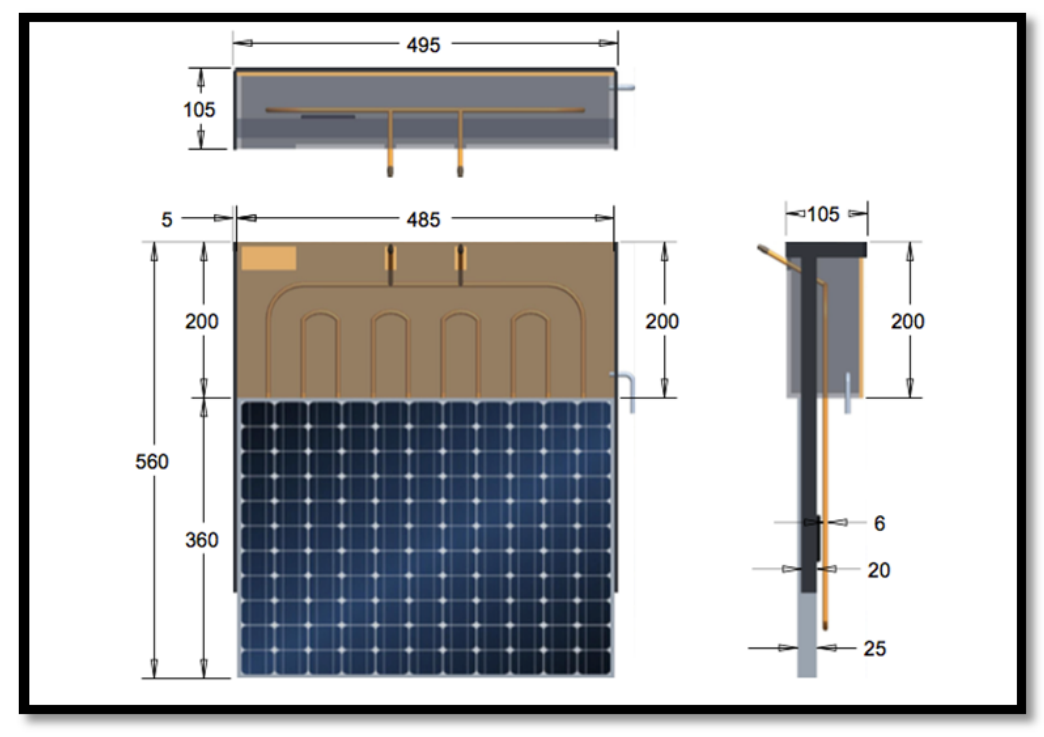

Figure 2. Multiview drawing of the prototype design

\subsection{Fabrication of Prototype}

After the prototype drawing has been confirmed, then, the selection of the material to be used should be selected. Some of the key factors that need to be included in the selection of the material to be used for prototype production are weather resistant materials, heavy-duty materials and economical materials. Table 1 below summarizes the components, material types and the description of the selected materials of the cooling system.

Table 1. Components and materials for prototype fabrication

\begin{tabular}{|c|c|c|}
\hline Components & Material Type & Descriptions \\
\hline Chamber & Clear Acrylic Sheet & $\begin{array}{c}\text { High impact strength } \\
\text { Low crazing rate } \\
\text { Resist sunlight damage and wrinkles } \\
\text { Transparent view } \\
\end{array}$ \\
\hline Support bracket & Copper Tube & $\begin{array}{c}\text { Rigid } \\
\text { Good weldability } \\
\text { Good formability } \\
\text { Strong is șej } \\
\text { Corrosion resistance } \\
\text { Machinability } \\
\text { High level of heat transfer } \\
\end{array}$ \\
\hline
\end{tabular}

After the material to be used has been determined, the next step is the fabrication process. Several tools were used such as copper tube bender, cutter and welder. Figure 5 shows the completed prototype. The storage tank acts as a chamber to release heat. In this study, the heat is released passively but is required, water can be flowed through the exposed pipe in the acrylic chamber. 


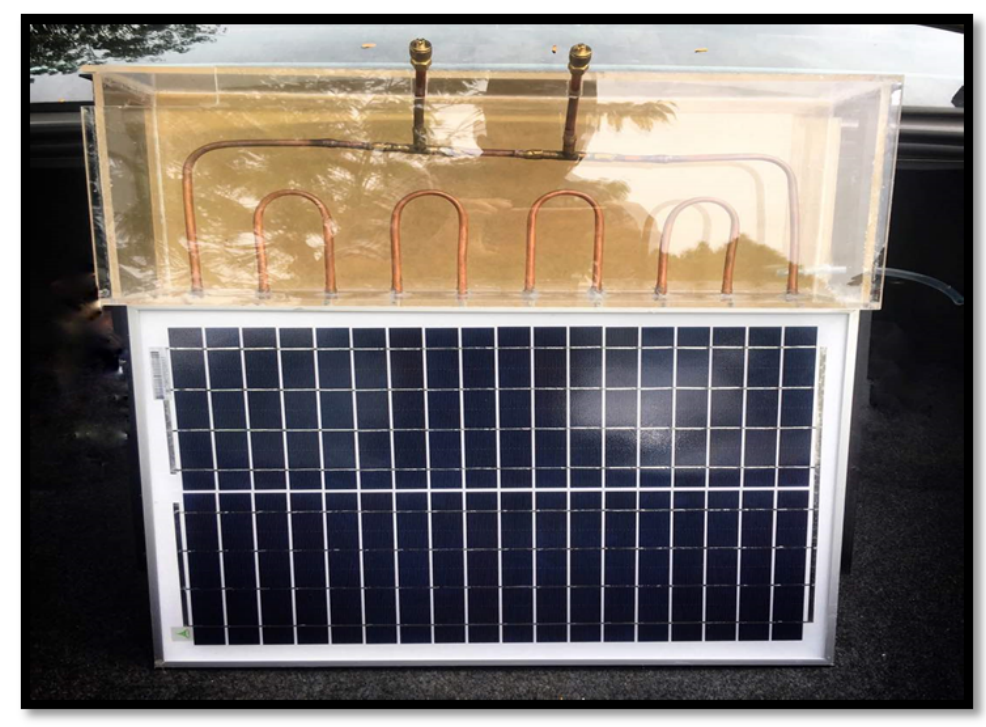

Figure 3. Front view of the prototype

Figure 5 above shows the completed assembly of the PV panel together with the pulsating heat pipe cooling system.

\subsection{Site Selection}

The experiment was conducted at TNB Research Kajang, due to the availability of an open area and measurement devices available.

\subsection{Experiment Setup}

Figure 6 shows the flow process of the experiment. To run this experiment, three types of measuring devices used are solar irradiance meter, multi-meter and current clamp meter. As the solar panel produces direct current (DC), each solar panel is connected with a $12 \mathrm{~W}$ LED bulb as a load. Some reading will be taken using the measuring devices. Readings will be taken every 5 minutes within 1 hour of experiment. The readings are temperature of solar panel $(\square C)$, solar irradiance $(\mathrm{W} / \mathrm{m} 2)$, output voltage for both solar panel (V) and output current for both solar panel (A). This experiment will use two solar panels. The solar panel labelled with blue tape is a solar panel without a cooling system, while a solar panel labelled with a red tape is a solar panel with a pulsating heat pipe cooling system.

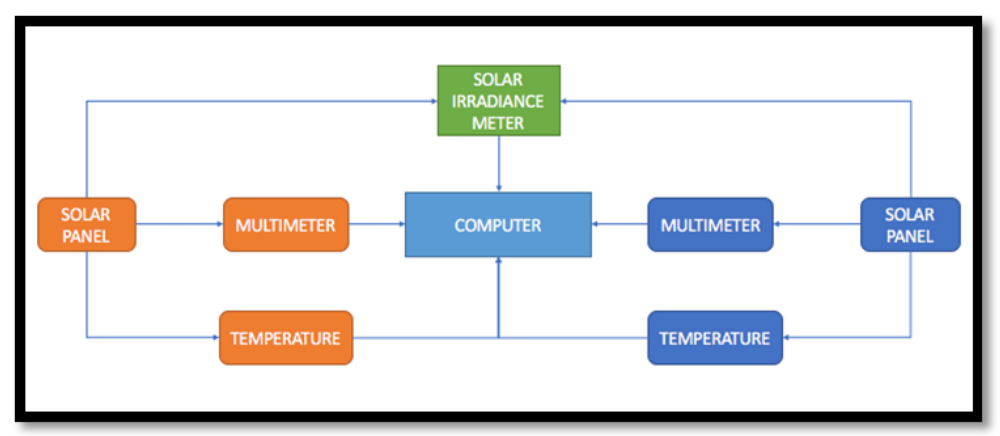

Figure 4. System connection for the experiment 


\subsection{Data Analysis} formula:

Using the data obtained from the meters, the electrical power output is calculated using the power

$$
P=I \times V
$$

The system efficiency, which is the electrical power output over the solar irradiance input is calculated using:

where:

$$
\eta=\frac{P_{\text {out }}}{P_{\text {in }}}=\frac{I \times V}{E \times A}=100
$$

$$
I=\text { current } ;=\text { voltage } E=\text { solar irradiance } A=\text { area of panels }
$$

Graphs of temperature vs. time and power output vs. time for both panels are plotted to compare the differences of the panel with and without any cooling method applied. The energy output for both panels are then calculated and compared, which is the sum of each power multiplied the time duration in hours for each time interval, or the formula:

$$
\begin{gathered}
E=\sum_{t=0}^{n} P \times t \\
t=\text { time } n=\text { final interval; } P=\text { electrical power output; }
\end{gathered}
$$

\section{RESULTS AND ANALYSIS}

The data collected is summarized in the Table 2. Table 2 shows the data recorded from the measurement devices for both panels with and without the heat pipe cooling method. The irradiance maintained below $1000 \mathrm{~W} / \mathrm{m} 2$ throughout the measurement. The data was recorded from 1205 at noon until

\begin{tabular}{|c|c|c|c|c|c|c|c|}
\hline \multirow[t]{2}{*}{$\underset{\Xi}{\Xi}$} & \multirow{2}{*}{ 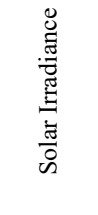 } & 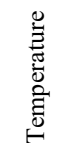 & $\underset{\Xi}{\Xi}$ & $\begin{array}{l}\stackrel{8}{5} \\
\frac{\Xi}{0} \\
0 \\
>\end{array}$ & 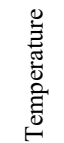 & $\underset{\Xi}{\stackrel{\Xi}{\Xi}}$ & $\begin{array}{l}80 \\
\frac{80}{ \pm} \\
0 \\
>\end{array}$ \\
\hline & & \multicolumn{3}{|c|}{ Without Heat Pipe } & \multicolumn{3}{|c|}{ With Heat Pipe } \\
\hline (Hour) & $(\mathrm{W} / \mathrm{m} 2)$ & $\left({ }^{\circ} \mathrm{C}\right)$ & (Amp) & (V) & $\left({ }^{\circ} \mathrm{C}\right)$ & (Amp) & $(\mathrm{V})$ \\
\hline 1205 & 992 & 35 & 0.6 & 16.12 & 35 & 0.6 & 16.7 \\
\hline 1210 & 957 & 40 & 0.73 & 15.59 & 39 & 0.7 & 16.8 \\
\hline 1215 & 900 & 42 & 0.77 & 15.6 & 41 & 0.78 & 15.7 \\
\hline 1220 & 887 & 42 & 0.89 & 15.1 & 39 & 0.89 & 15.8 \\
\hline 1225 & 886 & 44 & 0.79 & 15.8 & 39 & 0.82 & 15.7 \\
\hline 1230 & 916 & 48 & 0.82 & 14.9 & 40 & 0.87 & 15.7 \\
\hline 1235 & 954 & 50 & 0.87 & 14.9 & 40 & 0.98 & 15.8 \\
\hline 1240 & 989 & 51 & 0.92 & 14.8 & 44 & 0.99 & 15.9 \\
\hline 1245 & 992 & 48 & 0.98 & 14.9 & 44 & 0.98 & 15.8 \\
\hline 1250 & 912 & 49 & 0.97 & 14.8 & 44 & 0.98 & 15.9 \\
\hline
\end{tabular}
1250 with the interval of 5 minutes. The lowest irradiance recorded was $886 \mathrm{~W} / \mathrm{m} 2$ occurring at 1225 and the highest was $992 \mathrm{~W} / \mathrm{m} 2$ occurring at 1205 and 1245 . It can be seen that the general trend is that the temperature of the panel with heat pipe is lower compared to the one without.

Table 2. Measured data

The temperature difference between the two panels was calculated and plotted against the output current difference as shown in Figure 7 . It can be seen that the higher the temperature difference between the two panels, the higher the output current difference. Using linear regression, it can be seen that there is a high correlation between the two parameters, which has a coefficient of correlation (R) of 0.88 and a coefficient of determination (R2) of 0.7779 . Since the input irradiance is the same for both panels, it can be concluded that the higher the temperature of the panels, the higher the output current. 


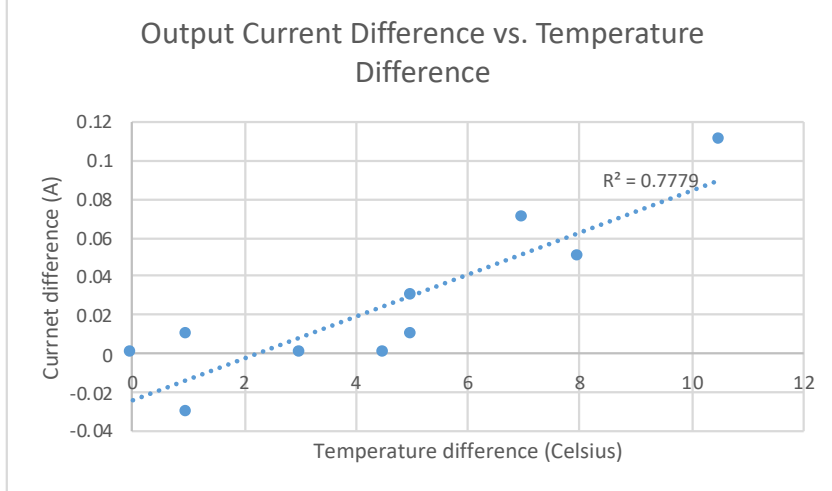

Figure 5. Graph of current difference vs. temperature difference

Table 3 shows the power output, energy output and panel efficiency calculated based on the data measured. It can be seen that throughout the time, the temperature of the panel with heat pipe cooling is consistently lower, having the minimum difference of 1 Celsius and the maximum difference of 10.5 Celsius at 1235 in the afternoon. The initial temperature difference is 0 Celsius due to the panel is exposed in the sun long enough to be affected. It can also be seen that the power output of the panel with heat pipe cooling consistently lower, with up to $2.5125 \mathrm{~W}$ more power output or $19.45 \%$ higher at $1235 \mathrm{pm}$. The energy output throughout the measurement period is $10.562 \mathrm{Wh}$ for the panel without heat pipe cooling and $11.409 \mathrm{Wh}$ for the panel with heat pipe cooling, which is $8.025 \%$ more. However, to evaluate the overall improvements of the performance, a longer period of experiment needs to be conducted.

Table 3. Calculated output

\begin{tabular}{|c|c|c|c|c|c|c|c|c|c|c|c|}
\hline \multirow[t]{2}{*}{$\stackrel{\Xi}{\Xi}$} & \multirow[t]{2}{*}{ 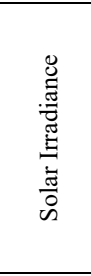 } & \multirow[t]{2}{*}{ 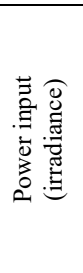 } & 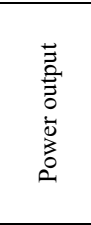 & 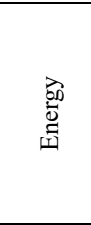 & 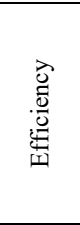 & 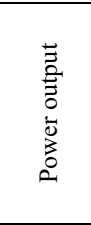 & 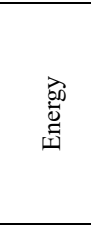 & 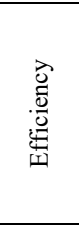 & \multirow{2}{*}{ 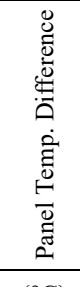 } & \multirow{3}{*}{ 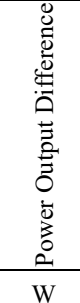 } & \multirow{3}{*}{ 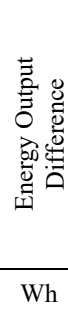 } \\
\hline & & & \multicolumn{3}{|c|}{ Without Heat Pipe } & \multicolumn{3}{|c|}{ With Heat Pipe } & & & \\
\hline (Hour) & $(\mathrm{W} / \mathrm{m} 2)$ & $\mathrm{W}$ & $\mathrm{W}$ & Wh & $\%$ & W & $\mathrm{Wh}$ & $\%$ & $\left({ }^{\circ} \mathrm{C}\right)$ & & \\
\hline 1205 & 992 & 173 & 9.672 & 0.81 & 5.584 & 10.02 & 0.835 & 5.785 & 0 & 0.348 & 0.029 \\
\hline 1210 & 957 & 167 & 11.381 & 0.95 & 6.811 & 11.76 & 0.980 & 7.038 & -1 & 0.379 & 0.032 \\
\hline 1215 & 900 & 157 & 12.012 & 1 & 7.644 & 12.246 & 1.021 & 7.793 & -1 & 0.234 & 0.020 \\
\hline 1220 & 887 & 155 & 13.439 & 1.12 & 8.678 & 14.062 & 1.172 & 9.080 & -3 & 0.623 & 0.052 \\
\hline 1225 & 886 & 155 & 12.482 & 1.04 & 8.069 & 12.874 & 1.073 & 8.322 & -5 & 0.392 & 0.033 \\
\hline 1230 & 916 & 160 & 12.218 & 1.02 & 7.639 & 13.659 & 1.138 & 8.540 & -8 & 1.441 & 0.120 \\
\hline 1235 & 954 & 167 & 12.963 & 1.08 & 7.782 & 15.484 & 1.290 & 9.296 & -10.5 & 2.521 & 0.210 \\
\hline 1240 & 989 & 173 & 13.616 & 1.13 & 7.885 & 15.741 & 1.312 & 9.116 & -7 & 2.125 & 0.177 \\
\hline 1245 & 992 & 173 & 14.602 & 1.22 & 8.431 & 15.484 & 1.290 & 8.940 & -4.5 & 0.882 & 0.074 \\
\hline 1250 & 912 & 159 & 14.356 & 1.2 & 9.016 & 15.582 & 1.299 & 9.786 & -5 & 1.226 & 0.102 \\
\hline \multicolumn{3}{|c|}{ Total Energy (Wh) } & \multicolumn{3}{|c|}{10.562} & \multicolumn{3}{|c|}{11.409} & \multicolumn{2}{|c|}{ Difference } & 0.848 \\
\hline
\end{tabular}

Figure 8 shows the electrical power output of both panels against time. It can be seen that the panel with heat pipe is continuously producing more power compared to the one without. It can also be seen that the highest difference of power output occurs at 1235, which is also the time at which the temperature difference is the highest, although the temperature is not the highest recorded. The highest panel temperature recorded is 51 Celsius at 1240, for the panel without heat pipe. 


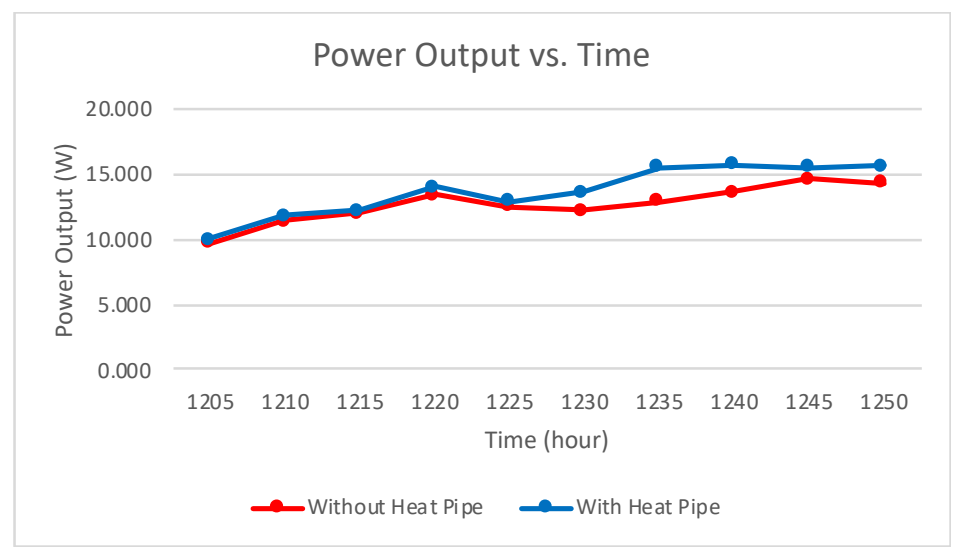

Figure 6. Graph of power output over time

Figure 9 shows the graph of panel efficiency against time. It can be seen that the panel with heat pipe is consistently higher in efficiency compared to the one without. The highest difference in efficiency also occurs at 1235 , which is the time at which the temperature difference is the highest between the two panels. Although the temperature is higher at the time, it can also be noted that the irradiance is also high, recorded to be above $900 \mathrm{~W} / \mathrm{m} 2$, so a higher input power is available.

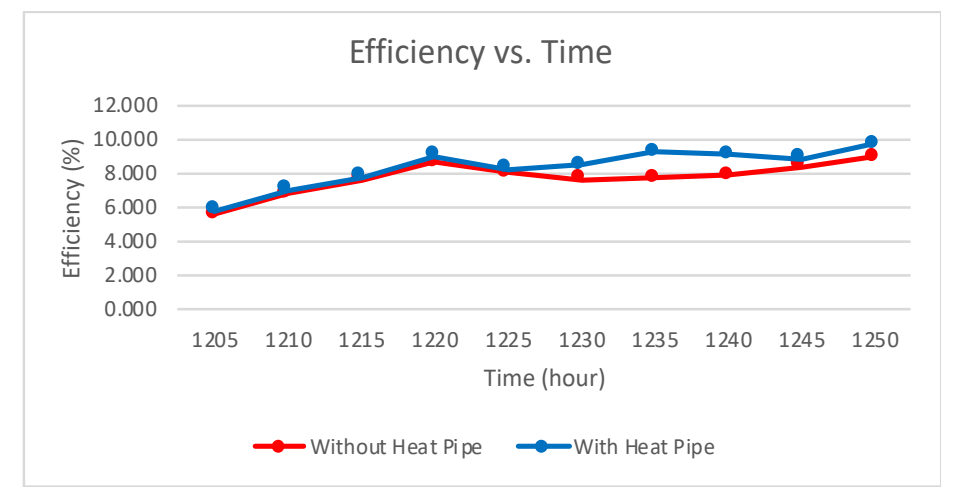

Figure 7. Graph of panel efficiency over time

\section{CONCLUSION}

This paper has presented the result of incorporating pulsating heat pipe on the back plate of a solar PV panel. The addition of pulsating heat does increase the performance output of the solar panel, with up to $19.45 \%$ more electrical power output and $8.025 \%$ energy produced. The temperature of the panel is lowered up to 10.5 Celsius. If the cost can be kept small compared to the overall cost of PV installation, there is potential of lowering the payback period of solar PV projects and increasing the return of investment. However, a lot more design work needs to be done and also the production method if the cooling method is to be applied at commercial scale. To better study the improvement offered by the pulsating heat pipe, a controlled environment is needed, which can give a controlled irradiance, ambient temperature and wind speed, at which one parameter can be manipulated at one time while the others are kept constant. This study looks at the output in the real-life environment. Using pulsating heat pipe requires no pumps for moving fluid, so it requires no external energy.

\section{ACKNOWLEDGEMENTS}

We would like to acknowledge TNB Research Sdn. Bhd. for providing the testing equipment and space. 


\section{REFERENCES}

[1] Official Website, "Sustainable Energy Development Authority Malaysia." [Online]. Available: http://seda.gov.my.

[2] T. H. Oh, S. Y. Pang, and S. C. Chua, "Energy policy and alternative energy in Malaysia: Issues and challenges for sustainable growth," Renew. Sustain. Energy Rev., vol. 14, no. 4, pp. 1241-1252, 2010.

[3] W. G. J. Van Helden, R. J. C. Van Zolingen, and H. A. Zondag, "PV Thermal systems: PV panels supplying renewable electricity and heat," Prog. Photovoltaics Res. Appl., vol. 12, no. 6, pp. 415-426, 2004.

[4] F. Grubisic-Cabo, S. Nizetic, and T. G. Marco, "Photovoltaic Panels : a Review of the Cooling," Trans. Famena XL, vol. 1, no. 1, pp. 63-74, 2016.

[5] S. Chander, A. Purohit, A. Sharma, S. P. Nehra, and M. S. Dhaka, "Impact of temperature on performance of series and parallel connected mono-crystalline silicon solar cells," Energy Reports, vol. 1, pp. 175-180, 2015.

[6] J. Siecker, K. Kusakana, and B. P. Numbi, "A review of solar photovoltaic systems cooling technologies," Renew. Sustain. Energy Rev., vol. 79, no. July 2016, pp. 192-203, 2017.

[7] R. Thaib, S. Rizal, Hamdani, T. M. I. Mahlia, and N. A. Pambudi, "Experimental analysis of using beeswax as phase change materials for limiting temperature rise in building integrated photovoltaics," Case Stud. Therm. Eng., vol. 12, no. July 2017, pp. 223-227, 2018.

[8] H. Alizadeh, R. Ghasempour, M. B. Shafii, M. H. Ahmadi, W. M. Yan, and M. A. Nazari, "Numerical simulation of PV cooling by using single turn pulsating heat pipe," Int. J. Heat Mass Transf., vol. 127, pp. 203-208, 2018.

[9] N. A. S. Elminshawy, A. M. I. Mohamed, K. Morad, Y. Elhenawy, and A. A. Alrobaian, "Performance of PV panel coupled with geothermal air cooling system subjected to hot climatic," Appl. Therm. Eng., vol. 148, no. October 2018, pp. 1-9, 2019.

[10] A. F. A. Castanheira, J. F. P. Fernandes, and P. J. C. Branco, "Demonstration project of a cooling system for existing PV power plants in Portugal," Appl. Energy, vol. 211, no. December 2017, pp. 1297-1307, 2018.

[11] S. Khandekar and M. Groll, "On the Definition of Pulsating Heat Pipes: An overview," Proc. 5th Minsk Int. Semin. (Heat Pipes, Heat Pumps Refrig., vol. 3, p. 12, 2003.

[12] Akachi, "Structure of Mico-heat Pipe," 5219020, 1993.

[13] Akachi, "Structure of Heat Pipe," 4921041, 1990.

[14] X. Tang, L. Sha, H. Zhang, and Y. Ju, "A review of recent experimental investigations and theoretical analyses for pulsating heat pipes," Frontiers in Energy, vol. 7, no. 2. pp. 161-173, 2013.

[15] S. Khandekar, "Thermo-hydrodynamics of Closed Loop Pulsating Heat Pipes," p. 154, 2004.

Indonesian J Elec Eng \& Comp Sci, Vol. 14, No. 1, April 2019 : 311 - 318 